\title{
Group Decision-Making
}

R. Scott Tindale and Jeremy R. Winget

Loyola University Chicago

This paper has been accepted for publication and may be cited as:

Tindale, R. S., \& Winget, J. R. (2019). Group Decision-Making. In Oxford Research Encyclopedia of Psychology. doi:10.1093/acrefore/9780190236557.013.262

Corresponding author: R. Scott Tindale, rtindal@luc.edu 


\section{Summary}

Group decisions are ubiquitous in everyday life. Even when decisions are made individually, decision-makers often receive advice or suggestions from others. Thus, decisions are often social in nature and involve multiple group members. The literature on group decision-making is conceptualized as falling along two dimensions: how much interaction or information exchange is allowed among the group members, and how the final decision is made. On one end, group decisions can be made simply by aggregating member preferences or judgments without any interaction among members, with members having no control or say in the final judgment. One the other end, groups' decisions can involve extensive member interaction and information exchanges, and the final decision is reached by group consensus. In between these two endpoints, various other strategies are also possible, including prediction markets, Delphi groups, and judge-advisor systems. Research has shown that each dimension has different implications

for decision quality and process depending on the decision task and context. Research exploring these two dimension has also helped to illuminate those aspects of group decision-making that can lead to better-quality decisions.

\section{Keywords:}

group decision-making, group performance, information exchange, decision strategies, social influence 
Human existence involves an ever-expanding array of choices and decisions. We are constantly deciding what, when, where, and how to enact various aspects of our behavioral repertoire. Although such decisions often are seen as individual endeavors, many, if not most decisions, involve a social or collective component. People often talk to friends or family members before making major purchases or deciding on a new job, and in the internet age almost any product available is associated with customer reviews and ratings as to its quality and worth. Companies launch new products and choose advertising strategies based on consumer surveys or focus groups. In addition, most organizations have executive committees or corporate boards that discuss and debate available options before decisions are made. Thus, rather than being an individual affair, we would argue that decision-making is often group-oriented, with many decisions made by, in, or with assistance from, groups. Over the past few decades, judgment and decision-making research has begun to focus more on the social components of decision contexts and have led to both new theoretical developments and interesting research findings (Kerr \& Tindale, 2004).

The fact that groups are involved in many decision contexts is both good (usually) and quite natural. By now, a very large literature exists demonstrating the "Wisdom of Crowds" (Surowiecki, 2004), or at least the typical performance advantage of groups over individuals (Kerr \& Tindale, 2004; Larrick \& Soll, 2006). For many task domains, the performance of a randomly selected individual provides a lower limit to group performance and, in most domains, groups consistently exceed this limit (Davis, 1969; Steiner, 1972). Groups, as compared to individuals working alone, are better able to reach correct solutions to problems (Laughlin, 1980; 1999), make more accurate hiring decisions (Tindale, 1989), receive better negotiation outcomes (Morgan \& Tindale, 2002), provide more accurate forecasts (Kerr \& Tindale, 2011), generate 
more creative ideas (Paulus \& Nijstad, 2003), receive higher scores on academic tests (Michaelson, Watson, \& Black, 1989), and recall information more accurately (Hinsz, 1990). Thus, decisions made by groups tend to lead to better outcomes by a number of criteria.

A number of authors have argued that the social nature of decisions stems from evolutionary adaptations to social living (e.g., Kameda \& Tindale, 2006). Our ancestral groups not only served to protect their members from predators, but also increased the availability of resources through shared efforts and better decision-making. Hastie and Kameda (2005) simulated huntinglocation choices among hunter-gatherer tribes using a series of potential decision rules. They found that a simple majority/ plurality rule (choose the hunting location with the greatest amount of support among the tribal hunters) performed exceptionally well while requiring few cognitive resources. Majority/ plurality rules consistently outperformed best-member rules, showing that group decisions tended to be better than even the most accurate tribal member.

However, there is also evidence that the superiority of groups is not a given (Janis, 1982; Kerr, MacCoun, \& Kramer, 1996; Simmons, Nelson, Galak, \& Frederick, 2011). In many cases, groups have been shown to make disastrous decisions with deadly consequences (e.g., the Challenger explosion, Bay of Pigs incident, instances of ethnic cleansing, etc.; Nijstad, 2009). Until recently, the theories used to explain the good decisions and actions of groups have differed from those used to explain the poor decisions and actions. However, recent attempts to identify the basic principles underlying group decision- making have begun to show that both good and bad decisions by groups may stem from the same underlying processes (Kerr \& Tindale, 2004; Tindale, Smith, Dykema-Engblade, \& Kluwe, 2012). In other words, basic group decision-making processes will often lead to good decisions, but in some decision contexts they 
can exacerbate individual-level biases and lead to decisions less accurate than those of a randomly selected individual.

Collective decisions can be made in various different ways following a number of different procedures. Two dimensions along which these different procedures can vary involve the degree of interaction/ information exchange among the group members and the way in which the final decision or judgment is actually achieved. For example, the CEO of an organization may individually poll a sample of his/her employees about some organizational issue and use the information to help him/her distinguish among various options. In such a situation, the members of the collective may not even know that others are involved, and the final decision may have nothing to do with their collective preferences. Many government officials are chosen via elections where citizens vote for the person of their choice. There may be little interaction or information exchange among the voters, but their collective choice will define the final outcome. At the opposite end of the spectrum, a corporate board may spend many hours discussing business decisions by exchanging information and opinions until a particular option gains enough support among the members to be considered the consensus choice. Research involving both dimensions has served both a prescriptive and descriptive function. Models of group decision-making can be used to describe how groups should make decisions as well as how they actually do make decisions. Both types of research have proven useful for understanding group decision processes and performance.

The description of the theory and research on group decision-making will begin with groups whose members do not interact to any great degree and move toward those with both greater interaction and decision control. The review will show that a number of basic processes underlie virtually all group decision contexts, but also demonstrate where different processes arise and 
how they may influence the types of decisions groups make. A substantial amount of this work will use individual decision-makers as the standard of comparison, allowing us to show where using groups will enhance decision performance as well as situations where decision performance will be diminished. Finally, ways to design and teach groups how to make better decisions is discussed.

\section{Simple Aggregation}

Although group decision-making is often conceptualized as a set of individuals discussing and reaching consensus on some course of action, many group decisions are not made that way. Often, members' preferences are simply aggregated by one member (or a person outside the group) and the aggregate is used as the group's position or choice. Elections or surveys are often used to guide decision-making in larger organizations where face-to-face interaction among all the members would be impossible or prohibitive. Usually such systems are justified based on fairness or equal representation of groups, but most of the research to date has shown that such systems can also be quite good at producing accurate judgments (Ariely et al., 2000; Armstrong, 2001; Hastie \& Kameda, 2005; Larrick \& Soll, 2006). This accuracy, relative to judgments made by individuals, Surowiecki's (2004) “wisdom of crowds," has been replicated many times in a number of diverse problem domains (Larrick \& Soll, 2006; Surowiecki, 2004). Ariely, et al. (2000) showed that, assuming pairwise conditional independence and random individual error distributions (although this assumption is rarely satisfied in many decision contexts), the average of $J$ probability estimates ( $J=$ the number of estimators) will always be better than any of the component individual estimates. In addition, as $J$ increases, the average will tend toward perfect calibration diagnosticity (accurate representation of the true state of affairs), even when 
information provided to the various estimators is less than optimal. In addition, Johnson et al. (2001) empirically showed the accuracy advantage of the average probability estimate to be robust over a number of conditions, even when individual estimates were not independent. Recent work on forecasting has shown that a simple average of multiple independent forecasts will perform better than individual experts and often perform as well as more sophisticated aggregation techniques (Armstrong, 2001).

Larrick and Soll (2006) have explained the advantage of simple averages over individual judgments using the concept of "bracketing." Assuming that the group member judgments are independent, different members will make somewhat different estimates with some of the estimates above the "true score" and others below it. Thus, the estimates "bracket" the true score. When this is true, it can be shown mathematically that the average of the multiple estimates will always be more accurate than the average individual judge. If the true score is well bracketed by the multiple estimates (near the median or average), the aggregate accuracy will be far superior to the typical individual judge. However, even if the true score is closer to one of the tails of the distribution, the average will still outperform the typical individual, though not to the same degree. Larrick and Soll (2006) also show that even when the true score is not bracketed by the estimates, the group (average) will do no worse than the typical individual judge.

Although the simple average is the most often used aggregation technique, there are others that also have been used to provide group-level responses. A number of authors have argued for medians as a viable, if not preferred, alternative to the mean (Black, 1958; Hora, Fransen, Hawkins, \& Susel, 2012; Kerr \& Tindale, 2011). In many circumstances, means and medians will be very similar, especially when large groups are used. However, when group size is small, medians are less sensitive to extreme member estimates and may provide a more accurate 
representation of the central tendency of the group. When decision problems involve discrete alternatives, aggregation systems often use the mode (majority/ plurality) to define the group response. There is considerable evidence that majority/ plurality rules do quite well in a number of decision situations and often perform better than a random individual baseline (Hastie \& Kameda, 2005; Kerr \& Tindale, 2004). In addition, Sorkin, West, and Robinson (1998) have shown that majority models come very close to optimal performance when group member expertise is not knowable.

Although central-tendency aggregation models have been shown to do quite well in various situations (Larrick \& Soll, 2006), a number of researchers have attempted to improve aggregate forecasts by modifying the aggregation procedure or the weights given to individual members (Aspinall, 2010; Budescu \& Chen, 2013; Lee, Zhang, \& Shi, 2011)). Some attempts have been made to use Bayesian models to aggregate multiple forecasts, though it is often difficult to define the appropriate prior probabilities and likelihood functions (see Budescu, 2006). Others have proposed weighting the opinions of more expert members higher than those with less expertise (Aspinall, 2010). However, regression to the mean and measurement error can lead to overweighting of supposed experts in future aggregations. Recently, Budescu and Chen (2013) formulated a method for improving group forecasts by eliminating group members whose forecasts detract from the group performance. They had group members make probabilistic forecasts for a variety of events and then assessed whether the group's forecast was better or worse when each group member was included in (or removed from) the aggregate. By only including those members whose forecasts showed a positive influence on accuracy, they consistently improved the accuracy of the group forecasts relative to the simple average and 
other less effective weighting schemes, and the improvements persisted for future judgments not used to define the inclusion criteria (see also Mellers et al., 2014).

\section{Aggregation With Limited Information Exchange}

Although simple aggregation tends to produce fairly accurate decisions, there is little chance for members to share information or defend their positions. In addition, group members often remain unaware of others' positions and the final group product. Although there is evidence that, often, little is gained by member exchanges (Armstrong, 2006; Lorenz, Rauhutb, Schweitzera, \& Helbing, 2011), it is difficult for members with particular insights or important information to have influence without some type of interchange among group members (Kerr \& Tindale, 2011). Obviously, full group deliberation (a topic discussed later) would allow members to share and defend their position. However, there is evidence that the most influential members in freely interacting groups are not always the most accurate or correct, because influence is driven by status or confidence (Littlepage et al., 1997). Thus, various approaches are compromise procedures where some information exchange is allowed, but pressures toward conformity and incidental influence are minimized.

Probably the most famous of these procedures is the Delphi Technique (Dalkey, 1969; Rowe \& Wright, 1999; 2001). This technique has been used in idea-generation and forecasting most often, but it has also been adapted to other situations (Rohrbaugh, 1979). The procedure starts by having a group of (typically) experts make a series of estimates, rankings, idea lists, and so on, on some topic of interest to the group or facilitator. The facilitator then compiles the list of member responses and summarizes them in a meaningful way (mean rank or probability estimate, list of ideas with generation frequencies, etc.). The summaries are given back to the 
group members and they are allowed to revise their initial estimates. The group members are typically anonymous and the summaries do not specify which ideas or ratings came from each member. This procedure allows information from the group to be shared among the group members but avoids conformity pressure or undue influence by high-status members. The procedure can be repeated as many times as seems warranted but is usually ended when few if any revisions are recorded. The final outcome can range from a frequency distribution of ideas to a choice for the most preferred outcome or the central tendency (mean or median) estimate. A number of related techniques (e.g., Nominal Group Technique, Van de Ven \& Delbecq, 1971) use similar procedures but vary in terms of how much information is shared and whether group members can communicate directly. Overall, the purpose of these procedures is to allow for some information exchange while holding in check potential distortions due to social influence. Research on the Delphi technique has tended to show positive outcomes. Delphi groups do better than single individuals and do at least as well as, if not better than, face-to-face groups (Rorhbaugh, 1979). They have also been found to work well in forecasting situations (Rowe \& Wright, 1999; 2001).

A more recent technique is the use of prediction markets (cf. Wolfers \& Zitzewitz, 2004). Much like financial markets, prediction markets use buyers' willingness to invest in alternative events (e.g., Obama will win vs. McCain will win in the 2008 US presidential election) as a gauge of their likelihood. They typically do not prohibit direct communication among forecasters/ investors/bettors, but in usual practice there is little such communication (if any). However, since the value placed on the assets is typically set in an open market of buyers and sellers, those already in (or out) of the markets can be informed and swayed by various market indicators (e.g., movements in prices, trading volume, volatility), and thus mutual social 
influence can occur through such channels. The simple "initial forecasts-group aggregation-final forecast" sequence does not really apply to this method very well; it is a much more dynamic and continuous aggregation process, where bids and offers can be made, accepted, and rejected by multiple parties, and the collective expectations of the "group" can continue to change right up to the occurrence of the event in question (e.g., an election). Except for those with ulterior motives (e.g., to manipulate the market, or to use the market as a form of insurance), investments in such markets are likely to reflect the investors' honest judgments about the relative likelihood of events. Members can use current market values to adjust their thinking and learn from the behavior of other members. However, such investment choices are not accompanied by any explanation or justification. Indeed, such investors may even have incentives to withhold vital information that would make other investors' choices more accurate (e.g., that might inflate the price of a "stock" one wants to accumulate). Thus, in terms of opportunities for mutual education and persuasion, prediction markets fall somewhere between statistical aggregation methods (which allow none) and face-to-face groups (which allow many).

Vroom and Yetton (1973) argued that one of the ways managers make decisions is through consultation; the decision is made by the manager but only after getting advice from important members of the team or organization. Sniezek and Buckley (1995) referred to this mode of social decision-making as the "Judge-Advisor" systems (JAS) approach. The judge is responsible for the final decision but he/she seeks out suggestions from various advisors. Such systems have recently received a fair amount of research attention (see Banaccio \& Dalal, 2006 for a review). Based on the research discussed above, unless the judge had far more expertise than an advisor, the judge should weight the advice equal to their own opinion. Although receiving advice usually does improve judges' decisions relative to when they receive no advice, a vast amount of 
research has shown that judges tend to weight their own opinions more than twice as much as the advice they receive (Larrick, Mannes, \& Soll, 2012). This has been referred to as "egocentric advice discounting" (Yaniv, 2004; Yaniv \& Kleinberger, 2000). This effect has been found to be extremely robust and has been replicated in a large number of decision situations with different types of judges and advisors (Banaccio \& Dalal, 2006).

Judges do take the expertise of the advisors into account when re-evaluating their position. Thus judges discount less when the advisors are known experts or their past advice has proved to be accurate (Goldsmith \& Fitch, 1997). Judges are also more likely to use advice when making judgments in unfamiliar domains (Harvey \& Fischer, 1997), and they learn to discount poor advice to a greater degree than good advice (Yaniv \& Kleinberger, 2000). However, judges are not always accurate in their appraisals of an advisor's expertise. Sniezek and Van Swol (2001) have shown that one of the best predictors of a judge's use of advice is advisor confidence, which is poorly correlated with advisor accuracy. Discounting has been found to be less for advice that is solicited by the judge than for advice simply provided (Gibbons, Sniezek, \& Dalal, 2003). In addition, judges discount less when the task is complex (Schrah, Dalal, \& Sniezek, 2006), when there are financial incentives for being accurate (Sniezek \& Van Swol, 2001), and when they trust the advisor (Van Swol \& Sniezek, 2005). However, discounting is present in virtually all JAS situations and it almost always reduces decision accuracy.

A number of different explanations for the egocentric discounting effect have been proposed. One of the earliest explanations was based on anchoring and adjustment (Tversky \& Kahneman, 1974). Harvey and Fischer (1997) argued that the judge's initial estimate served as an anchor and judges simply did not adjust enough once provided with the advice. However, studies have shown the discounting effect even when no initial evaluation is present upon which 
to anchor (Banaccio \& Dalal, 2006). Yaniv (2004) has argued that the effect is due to the information advantage judges have about their own estimates. Judges should know why they chose their initial position, yet may know very little about why advisors gave the advice they did. Yaniv and Choshen-Hillel (2012) showed that forcing judges to choose initial positions based on virtually no information drastically reduced the discounting effect. However, Soll and Larrick (2009) found almost no effect of varying the amount of information judges had about the advisors' reasons for their choices. Krueger (2003) has argued that the effect is simply another instance of a general egocentric bias that has shown up in many domains of judgment. The bias leads people to focus their attention on certain aspects of the self and they typically perceive themselves as more capable than others on average. Larrick, Mannes, and Soll (2012; see also Soll \& Mannes, 2011) also argue that judges' positions are owned by them and become part of the self, thus making them difficult to give up. The egocentric discounting bias is similar to phenomena found with actual interacting groups who have reached a consensus judgment. When individual members are asked to state their private positions after group discussion, these final judgments tend to adjust back toward their initial positions (Kameda, Tindale, \& Davis, 2003).

\section{Fully Interacting Groups}

Most of the research on group decision-making has focused on groups where the members meet together face-to-face and discuss the particular decision problem until they reach consensus. Early research in this area tended to focus on member preferences as the major feature predicting group decision outcomes (Davis, 1973; Kameda, Tindale, \& Davis, 2003). More recent research has focused on how groups process information (Hinsz, Tindale, \& Vollrath, 1997) and the degree to which available information is used by the group (Brodbeck, Kerschreiter, Mojzisch, 
Frey, D., \& Shulz-Hardt, 2007; Lu, Yuan, \& McLeod, 2012). More recently still, the motivational aspects of groups and group members have begun to receive attention (De Dreu, Nijstad, \& Van Knippenberg, 2008).

Kameda, Tindale, and Davis (2003; see also, Tindale \& Kameda, 2000) have proposed that the concept of "social sharedness" underlies many of the common findings associated with group consensus. Social sharedness is the idea that task-relevant cognitions (broadly defined) that the members of a group have in common, or share, exert a greater influence on the group than do similar constructs that are not shared among the members. The cognitions that are shared can vary from preferences for decision alternatives or information about the alternatives to heuristic information-processing strategies that the members cannot even articulate. However, the greater the degree of sharedness for a particular task relevant cognition, the greater the likelihood that it will influence the group decision. In general, social sharedness is often adaptive and probably evolved as a useful aspect of living in groups (Kameda \& Tindale, 2004). However, a shift in context in which the shared cognition is inappropriate to the current situation can lead groups to make poor decisions. We will attempt to elucidate how social sharedness functions in groups' decision-making contexts and how/when it helps vs. hinders group decision accuracy.

\section{Group Consensus as Combining Preferences.}

Early work on group decision-making tended to focus on the distribution of initial member preferences and how such preferences get combined into a group, or collective, response (Davis, $1969 ; 1973$; Steiner, 1972). This is known as the "combinatorial approach" to group decisionmaking (Davis, 1982). One of the most widely used frameworks under this approach has been social decision scheme (SDS) theory (Davis, 1973). SDS theory assumes that a set of discrete 
decision alternatives are known by the group members and that each member favors a particular alternative at the beginning of deliberation. It then attempts to describe the group consensus process using a matrix of conditional probabilities mapping different member preference distributions to different consensus choices made by the group. For example, in a six-person group choosing between two decision alternatives (e.g., guilty vs. not guilty in a jury), there are seven ways in which the group members might initially array themselves across the alternatives: six voting guilty and none not guilty, five voting guilty and one not guilty, ... none voting guilty and six not guilty. Given a population of potential group members in which some proportion favors one alternative over the other (e.g., $40 \%$ favor guilty and $60 \%$ favor not guilty), the likelihood of each initial preference distribution is estimable. The SDS matrix then maps each initial preference distribution to a distribution of group outcomes based on theory or a set of assumptions concerning the consensus process by which members' initial preferences are reconciled. The SDS matrix can be used to prescribe what a group would do given certain theoretical assumptions, or it can describe what groups actually did in studies on group decisionmaking.

One of the key findings from the group decision-making literature using this framework is that majority/ plurality models do a fairly good job of representing the data from many group decision-making studies (Kerr \& Tindale, 2004; Kameda, Tindale, \& Davis, 2003). Although some contexts are better described by higher order majorities (e.g., criminal mock juries are well described by two to three majority models), in most types of decisions the position with the largest support faction tends to be chosen by the group. Kameda et al. (2003) have argued that majority/ plurality models reflect social sharedness at the preference level. One of the key aspects of majority/ plurality processes is that they tend to amplify in the group distribution those 
response tendencies that are prevalent at the individual level. Thus, in situations where the outcome of a decision can be defined as good or bad (or at least better or worse) by some criteria, a majority/ plurality process could lead groups to make better decisions than the average individual when individuals tended toward the "good" response alternative. However, exactly the same process could lead groups to make worse decisions than the average individual when individual preferences tended in that direction. Since the basic majority/ plurality process pushes the group in the direction initially favored by most of its members, it can lead to either good or poor decisions, depending on how members initially lean.

Fortunately, it appears that majority/ plurality processes tend to work quite well in many natural decision settings involving groups (Hastie \& Kameda, 2005; Sorkin, Hays, \& West, 2001; Sorkin, West, \& Robinson, 1998). Hastie and Kameda (2005) compared a variety of different ways groups could choose to move forward in an uncertain environment with many different response options. Overall, they found that a simple majority/ plurality process (i.e., going with the alternative with the greater degree of support) was more accurate than any other decision rule with similar computational complexity. Majority models did even better than bestmember models (going with the alternative preferred by the person whose choices have been most accurate in the past) and performed similarly to models that required much greater levels of computation (e.g., weighted averaging models based on past performance). Hastie and Kameda argued that the generally high levels of accuracy combined with the low computational load may explain why majority processes are so pervasive in social aggregates.

Majority/ plurality models are well defined when decision alternatives are discrete and groups are asked to choose one of the possible alternatives. However, many group decision tasks require groups to reach consensus on a point along a continuum (e.g., amount of money to invest 
or an estimation of the likelihood of some event) where it is unlikely that members' specific positions will overlap. Thus, majority/ plurality models of group choice are not appropriate for groups making ratings or estimations (Stasser \& Dietz-Uhler, 2001). Although a variety of models can be (and have been) applied to these types of situations (see Grofman \& Owen, 1986; Hinsz, 1999 for examples), we will focus mainly on three that have received a reasonable amount of empirical support.

One of the most basic models of group judgment is a simple arithmetic average. Assuming each group member starts discussion with a well-defined preference point, and assuming each member is equally influential, the mean of the initial distribution seems a reasonable compromise. It is also possible that means or other central tendency points serve as focal points (Schelling, 1960) and provide a salient resolution point for resolving preference differences. A number of studies have found that a simple averaging model provides a decent approximation of final group outcomes (Gigone \& Hastie, 1993), especially when groups are making multiple judgments in a limited timeframe.

Another model that has fared well empirically is the median model (Black, 1958; Crott et al., 1991; Davis et al., 1997; Laughlin, 2011). Black's (1958) work on social choice models showed that median positions form equilibria under certain circumstances, and thus were likely to be stable group choice outcomes. His Median Voter Theorem posited that when member preference curves are single peaked (i.e., each member has a single best point along the response continuum and a member's evaluation of other points on the continuum are relatively lower as a function of their distance from that best point), the median of the members' initial preferences is the most stable outcome (see Laughlin, 2011 for a more thorough discussion of social choice models generally). Crott et al. (1991) showed that a median model could explain choice shifts 
and provided a very good fit to group consensus data on choice dilemma items. Davis et al. (1997) also found a median model to provide a good fit to damage award judgments by mock civil juries. Davis (1996) also derived a group consensus model for continuous response dimensions called the Social Judgment Schemes (SJS) model. The model assumes that the amount of influence a particular group member has on the final group response is an inverse exponential function of the sum of the distances from that member's position to all other members' positions. Thus, members who are most similar to other members on the response dimension have greater influence on the final group response than do members whose preferences are less similar to other members overall (see Davis, 1996; Kameda, Tindale, \& Davis, 2003 for a more formal discussion of the model).

\section{Group Consensus Through Information Processing}

A major theme and dominant paradigm underlying much of the work on group decision-making and performance over the past 25 years had its start with a paper by Stasser and Titus (1985). Using a paradigm called the "hidden profile," Stasser and Titus showed that information that was initially shared by all of the group members was much more likely to be brought up during group discussion and was much more influential in the final group decision than was information held by only one member. By giving all the positive information about an inferior alternative to all members, and dividing the greater amount of positive information about a superior alternative among the group members so that each member only has part of it, Stasser and Titus showed that groups rarely shared enough of the unshared information to allow the group to realize that their initial consensus alternative was not as good as one of the others they could choose. When all of the information was shared by all members, groups easily found the superior alternative. The 
"shared information" or "common knowledge" effect (Gigone \& Hastie, 1993; Stasser \& Titus, 1985, 1987), as it came to be called, has been replicated hundreds of times, and the hidden profile paradigm has dominated group decision-making research ever since (see Brodbeck, Kerschreiter, Mojzisch, Frey, \& Shulz-Hardt, 2007 for review).

Probably the main reason the initial finding had such a profound impact on the field was that different information provided by different group members was seen as one of the key features of group processes that allowed groups to outperform individuals (Davis, 1969; Vinokur \& Burnstein, 1974). Although there is now a fair amount of evidence that groups do in fact perform better if their members share their unique information (Brodbeck et al., 2007), it is also quite clear that groups do not do this naturally in many settings (Stasser, 1999). The fact that shared, as opposed to unshared, information plays a much larger role in most group-decision settings definitely changed the way most researchers thought about groups and led to many studies attempting to better understand the phenomenon and discover ways to increase information sharing in groups.

Most of the current research findings have been nicely encapsulated by Brodbeck et al. (2007) in their Information Asymmetries Model of group decision-making. The model categorizes the various conditions that lead to poor information processing in groups into three basic categories. The first category, negotiation focus, encompasses the various issues surrounding initial member preferences. If groups view the decision-making task mainly as a negotiation, members negotiating which alternative should be chosen tend to focus on alternatives and not on the information underlying them. The second category, discussion bias, encompasses those aspects of group discussion that tend to favor shared vs. unshared information (e.g., items shared by many members are more likely to be discussed). The third category, 
evaluation bias, encompasses the various positive perceptions associated with shared information (e.g., shared information is more valid, sharing shared information leads to positive evaluations by other group members). All three categories are good descriptions of typical group decisionmaking and can lead to biased group decisions and inhibit cross-fertilization of ideas and individual member learning (Brodbeck et al., 2007).

A key aspect of Brodbeck and colleagues' model is that the various aspects of information processing in typical groups only lead to negative outcomes when information is distributed asymmetrically across group members, as when a hidden profile is present. Although such situations do occur and groups can make disastrous decisions under such circumstances (Janis, 1982; Messick, 2006), they are not typical of most group decision environments. In situations where members have independently gained their information through experience, the shared information they have is probably highly valid and more useful than unique information or beliefs held by only one member. Thus, the fact that members share preferences and information in many group decision contexts is probably adaptive and has generally served human survival well (Hastie \& Kameda, 2005; Kameda \& Tindale, 2006). In addition, groups are often (but not always) sensitive to cues in the environment that indicate that information is not symmetrically distributed (Brauner, Judd, \& Jacquelin, 2001; Stewart \& Stasser, 1998). Although minorities often are not very influential in groups, if minority members have at their disposal critical information that others do not have and that implies the initial group consensus may be wrong, other group members will pay attention to them. And, as discussed later, minority members who favor superior alternatives in environments where the superiority can be demonstrated can be very persuasive and lead majorities to switch their preferences (Laughlin \& Ellis, 1986). 
Given the pervasiveness of the shared information effect, a fair amount of research has focused on how to increase the likelihood that all relevant information is brought up during group discussion. One partial remedy is to make sure that groups have a record of all of the information present during group discussion (Sheffey et al., 1989). There is some recent evidence that group support systems can aid in this regard by allowing greater access to such information (Haseman \& Ramamurthy, 2004). As noted earlier, groups that share an accuracy, or problem-solving orientation to the decision problem bring up more unique information and perform better than groups with a consensus orientation (Postmes et al., 2001; Stewart \& Stasser, 1995; more on this topic will be discussed later under shared group motivation). Setting up a norm of information sharing, or having a leader who encourages and stimulates information exchange throughout the process, have shown promise in terms of greater information sharing and better performance (Larson, Foster-Fishman, \& Franz, 1998). Also, instructing group members to avoid forming initial impressions or preferences, and not allowing such preferences if present to be shared early in the discussion, has also been shown to be helpful (Larson et al., 1998; Mojzisch et al., 2010). Setting up a transactive memory system (Wegner, 1987) where certain group members are responsible for certain types of information also has been shown to help groups process more information (Stasser, Vaughan, \& Stewart, 2000). Groups that structure their tasks such that information is exchanged completely before any discussion of preferences or final decisions also tend to perform better (Brodbeck et al., 2002). The main things that seem to be important are a focus on information rather than preferences, memory aids or reduced information load per group member, and a focus on accuracy over consensus (Brodbeck et al., 2007). 
Specific pieces of information (and preferences) are not the only types of cognitions that group members can share (Resnick, Levine, \& Teasley, 1991; Tindale \& Kameda, 2000). Laughlin $(1980,2011)$ has argued that one of the reasons that groups are better problem-solvers than individuals is that group members often share a conceptual system that allows them to realize when a proposed solution is correct within that system. This shared conceptual system, or background knowledge, is what allows a minority member with a correct answer to influence a larger incorrect faction to change its preference to the correct alternative. Such situations are well described by SDS models called "Truth Wins" and "Truth Supported Wins" (Laughlin, 1980). Truth Wins predicts that any group that has at least one member with the correct answer will be able to solve the problem correctly (Laughlin, 1980). Truth Supported Wins argues that at least two members of the group must have the correct answer in order for the group to solve the problem correctly (Laughlin, 1980). For groups with more than four members, both models predict minority influence for minorities with the correct answer. Laughlin and Ellis (1986) proposed that such minority influence processes are likely to occur for demonstrable or "intellective" tasks (those that have a demonstrably correct solution) and that the shared conceptual system is a key component of demonstrability. For "judgmental" tasks (those without a demonstrably correct solution), majority/ plurality processes are more likely to occur.

Tindale, Smith, Thomas, Filkins, and Sheffey (1996) argued that the shared conceptual system underlying demonstrability is one instance of what they referred to as "shared task representations." They defined a shared task representation as "any task/ situation relevant concept, norm, perspective, or cognitive process that is shared by most or all of the group members" (Tindale et al., 1996, p. 84). "Task/ situation relevant" means that the representation must have implications for the choice alternatives involved, and the degree to which a shared 
representation affects group decision processes and outcomes will vary as a function of its relevance. Its influence will also vary by the degree to which it is shared among the group members - the greater the degree of sharedness (the more members who share it), the greater its influence. If no shared task representation exists, or if multiple conflicting representations are present, groups will tend to follow a symmetric majority/ plurality process. However, when a shared task representation does exist, the group decision process will tend to become asymmetric in favor of alternatives that fit within or are supported by the representation. Under such conditions, majorities/ pluralities favoring an alternative consistent with the shared representation are more powerful than are identically sized majorities/ pluralities favoring alternatives that are not consistent with or supported by the representation. In addition, minorities favoring an alternative consistent with the shared representation can sometimes be more influential than majorities favoring an alternative inconsistent with the shared representation. Although Laughlin's work (1980; Laughlin \& Ellis, 1986) is probably the strongest example of the effects of shared representations, a number of other potent examples exist. For example, much of the work on mock-jury decision-making (MacCoun \& Kerr, 1988; Tindale, Nadler, Krebel, \& Davis, 2001) has shown that "not guilty" is an easier verdict to defend than "guilty." In other words, majorities favoring guilty are less successful than are majorities favoring not guilty. In addition, juries that are evenly divided between guilty and not guilty, and even some juries with a sizable minority favoring not guilty, reach a not guilty verdict much of the time (MacCoun \& Kerr, 1988). MacCoun and Kerr showed that this asymmetry toward not guilty only occurs when juries are provided with a "reasonable doubt" verdict criterion. Tindale et al. (1996) argued that the reasonable doubt criterion serves as a shared task representation that tells jurors that they should look for and pay attention to reasonable doubts, and if they exist, they 
should vote not guilty. It is possible that the extreme punitive damage awards reported by Sunstein et al. (2002) may have been a function the shared sense of outrage jurors felt for those cases. More recent research has shown that religion can also work as a shared task representation. Smith, Dykema-Engblade, Walker, Niven, and McGrough (2000) showed that minorities against the death penalty were persuasive in altering majority positions on the issue when they framed their arguments in terms of religion ("Thou shalt not kill"), whereas other types of arguments were effective. The shared religious orientations of the group members provided a context within which religious arguments could be very effective even though they conflicted with the majority's initial preference. Tindale (1993) has shown that shared intuitive decision biases can also work as shared task representations and can lead to groups exacerbating such biases.

\section{Shared Motivations in Groups}

Motivation in groups has been a topic of interest in social psychology since its earliest days as a field of inquiry (Triplett, 1898). Many studies have focused on how groups affect the amount of effort expended by their members, and both motivation gains and losses have been demonstrated (Kerr \& Tindale, 2004; Weber \& Hertel, 2007). Motivation has also been an important topic in group as well as individual decision-making, and until recently the basic motivational assumption was hedonism. Many models of collective decision-making use basic game theoretic, or utility maximization, principles to explain how members both choose initial preferences and move toward consensus (Kahn \& Rapoport, 1984). Thus, much of the early work on group decision-making tended to treat individual group members as players in a utility-maximization game (Budescu, Erev, \& Zwick, 1999). Game theory approaches are quite prevalent and also 
quite useful for understanding social behavior (Kameda \& Tindale, 2006), but other motives more associated with the group level of analysis have also been found to be important (Levine \& Kerr, 2007). In addition, many of these motivations were discovered because social behavior did not follow game theoretic expectations (Dawes, van de Kragt, \& Orbell, 1988).

Probably the most heavily researched of these more recent motives in groups involves the ingroup bias (Hogg, 2018). There is now substantial evidence that when group members think about themselves as a group (thus they share a social identity), they begin to behave in ways that protect the group from harm or enhance its overall welfare. Many of the implications of this bias are positive for the group, but there are situations where it prevents groups from making good decisions. For example, groups are more likely than individuals to lie about preferences and resources in a negotiation setting (Stawiski, Tindale, \& Dykema-Engblade, 2009). Probably the most prominent example where protecting or enhancing the group's welfare leads to less than optimal decisions is the inter-individual — intergroup discontinuity effect (Wildschut et al., 2003). This effect was initially demonstrated by McCallum et al. (1985) who compared individuals to groups when playing a Prisoner's Dilemma game. The Prisoner's Dilemma game is a mixed-motive game where the dominant or individually rational response is not to cooperate with the other player. However, when both players make the non-cooperative choice, they both do poorly. The only collectively rational choice is for both players to cooperate, which leads to the greatest collective payoff and to moderate positive gains for each player. When two individuals play the game and are allowed to discuss the game before making choices, they both end up cooperating better than $80 \%$ of the time. However, when two groups play the game and each group must choose between cooperation and non-cooperation, groups quite often choose not to cooperate. Over multiple plays of the game, groups end up locked in the mutual non- 
cooperation payoff and earn far worse payoffs compared to the inter-individual situation. This effect has been replicated many times using different types of mixed-motive game structures and different sized groups (see Wildschut et al., 2003 for a review).

Research has shown that both fear and greed come into play when groups play these types of games (Wildschut et al., 2003). Groups, more than individuals, tend to be fearful of being taken advantage of by the other group. However, even when playing the game against a single individual, groups still are more likely to choose non-cooperation, thinking they can take advantage of the more cooperative individual (Morgan \& Tindale, 2002). Thus, groups both protect themselves by choosing non-cooperation, but also attempt to insure that they do as well or better than the other player. Interestingly, there is little evidence that the effect stems from wanting to hurt the outgroup. Recent studies by Halevy et al. (2008) show that in games that include a choice that only aids the ingroup and has no effect on the outgroup or other player, groups virtually always choose this option over options that only hurt the outgroup or that both aid the ingroup and hurt the outgroup.

De Dreu, Nijstad, and Van Knippenberg (2008) developed a model of group judgment and decision-making based on the combination of epistemic and social motives. Called the "motivated information processing in groups" model (MIP-G), the model argues that information processing in groups is better understood by incorporating two somewhat orthogonal motives; high vs. low epistemic motivation, and pro-social vs. pro-self motivation. Earlier work on negotiation had shown that negotiators that share both high epistemic motivation and a pro-social orientation were better able to find mutually beneficial tradeoffs and reach better integrative agreements as compared to negotiators with any other combination of motives (De Dreu, 2010). Recent research now shows that the same appears to hold true for groups working cooperatively 
to solve a problem or make a decision. According to the model, high epistemic motivation involves a goal to be accurate or correct which should lead to deeper and more thorough information search and analysis (Kruglanski \& Webster, 1996). Work on the information sharing effects has consistently demonstrated that instilling a goal of accuracy or defining the task in terms of solving a problem both increase information sharing (Postmes et al., 2001; Stewart \& Stasser, 1995). Members high in prosocial motivation help to insure that all types of information held by each member are likely to be disseminated, rather than just information supporting the position held by an individual member. Recent research showing that members focusing on preferences rather than information tends to impede information sharing is quite consistent with this assertion (Mojzisch \& Schulz-Hardt, 2010). The model predicts that group information processing will only approach optimal levels when group members are high on both epistemic motivation and pro-social orientation. This is because that is the only combination which produces both systematic and thorough processing of information in an unbiased manner. The model does a good job of explaining a number of well replicated findings and has fared well in the few direct attempts to test it (Bechtoldt, De Dreu, Nijstad, \& Choi, 2010; De Dreu, 2007).

\section{Summary and Conclusions}

Overall, research supports the notion that groups are typically good decision-makers. However, it has also shown that they are rarely optimal and can make rather poor decisions under certain circumstances. Fortunately, research has also begun to identify a number of factors that can be used to either train or design groups leading to better decision quality. First, groups tend to be most accurate when their members hold diverse perspectives. Recent research has shown that increasing diversity even beyond the level obtained from a random representative sample will 
improve the accuracy of group estimates (Davis-Stober, Budescu, Dana, \& Broomell, 2014). When group interaction is involved, the members must also be open to diverse opinions and be willing to express positions when they differ from those of other group members (Homan, van Knippenberg, van Kleef, \& De Dreu, 2007). Groups will also be wiser when they are composed of wiser members (Budescu \& Chen, 2014; Laughlin, 2011; Mellers et al., 2014). Thus, insuring that groups have members of high expertise or ability on the requisite task is important. In addition, group members should be highly motivated for the group to make accurate decisions (De Dreu et al., 2008). Although groups can often be wise without member interactions, allowing members to exchange information and ideas tends to do little harm and can allow groups to take advantage of particularly good ideas uniquely held by few members (Kerr \& Tindale, 2011; Laughlin, 2011; Mellers et al., 2014). Group interaction only tends to create problems for groups in situations where they are likely to be less than wise (Kerr \& Tindale, 2004). When group members all share a biased representation of the decision environment, group discussion tends to exacerbate such biases (Tindale et al., 1996). Groups also can be unwise when they make decisions that have direct implications for the well-being of the group (Morgan \& Tindale, 2002; Stawiski et al., 2009). Thus, groups will be wiser to the degree that there are no incentives for members other than being as accurate as possible. Finally, groups are wiser when their members exchange all of the available information rather than just focusing on information they all share (Brodbeck et al., 2007). Thus, if training and design procedures can increase diversity of perspectives, help identify expertise, allow for open and thorough exchanges of information and ideas, identify or reduce shared biases, and increase motivation for accuracy, then they will help groups to take full advantage of their wisdom. 


\section{References}

Ariely, D., Tung Au, W., Bender, R. H., Budescu, D. V., Dietz, C. B. . . Zauberman, G. (2000). The effects of averaging subjective probability estimates between and within groups. Journal of Experimental Psychology: Applied, 6, 130-147.

Armstrong, J. S. (2001). Principles of forecasting: A handbook for researchers and practitioners. Boston: Kluwer Academic.

Armstrong, J. S. (2006). Should the forecasting process eliminate face-to-face meetings? Foresight: The International Journal of Applied Forecasting, 5, 3-8.

Aspinall, W. (2010). A route to more tractable expert advice. Nature, 463, 264-265.

Bechtoldt, M. N., De Dreu, C.-K. W., Nijstad, B. A., \& Choi, H. S. (2010). Motivated information processing, epistemic social tuning, and group creativity. Journal of Personality and Social Psychology, 99, 622-637.

Black, D. (1958). The theory of committees and elections. Cambridge, UK: Cambridge University Press.

Bonaccio, S., \& Dalal, R. S. (2006). Advice taking and decision making: An integrative literature review and implications for the organizational sciences. Organizational Behavior and Human Decision Processes, 101, 127-151.

Brauner, M., Judd, C. M., \& Jacquelin, V. (2001). The communication of social stereotypes: The effects of group discussion and information distribution on stereotypic appraisals. Journal of Personality and Social Psychology, 81, 463-471.

Brodbeck, F. C., Kerschreiter, R., Mojzisch, A., Frey, D., \& Schulz-Hardt, S. (2002). The dissemination of critical, unshared information in decision-making groups: The effects of pre-discussion dissent. European Journal of Social Psychology, 32, 35-56. 
Brodbeck, F. C., Kerschreiter, R., Mojzisch, A., Frey, D, \& Schulz-Hardt, S. (2007). Group decision making under conditions of distributed knowledge: The information asymmetries model. Academy of Management Review, 32, 459-479.

Budescu, D. V. (2006). Confidence in aggregation of opinions from multiple sources. In K. Fiedler, \& P. Juslin (Eds.), Information sampling and adaptive cognition (pp. 327-352). Cambridge, U.K.: Cambridge University Press.

Budescu, D. V., \& Chen, E. (2014). Identifying expertise and using it to extract the wisdom of crowds. Management Science, 62, 267-280.

Budescu, D. V., Erev, I., \& Zwick, R. (Eds.). (1999). Games and human behavior. Mahwah, NJ: Lawrence Erlbaum Associates.

Crott, H. W., Szilvas, K., \& Zuber, J. A. (1991). Group decision, choice shift, and group polarization in consulting, political and local political scenarios: An experimental investigation. Organizational Behavior and Human Decision Processes, 49, 22-41.

Dalkey, N. C. (1969). An experimental study of group opinion: The Delphi method. Futures, 1, $408-426$.

Davis, J. H. (1969). Group performance. New York, NY: Addison-Wesley.

Davis, J. H. (1973). Group decision and social interactions: A theory of social decision schemes. Psychological Review, 80, 97-125.

Davis, J. H. (1982). Social interaction as a combinatorial process in group decision. In H. Brandstatter, J. H. Davis, \& G. Stocker-Kreichgauer (Eds.), Group decision making (pp. 27-58). London, UK: Academic Press. 
Davis, J. H. (1996). Group decision making and quantitative judgments: A consensus model. In E. Witte \& J. H. Davis (Eds.), Understanding group behavior: Consensual action by small groups, vol. 1 (pp. 35-59). Mahwah, NJ: Lawrence Erlbaum Associates.

Davis, J. H., Au, W., Hulbert, L., Chen, X., \& Zarnoth, P. (1997). Effect of group size and procedural influence on consensual judgment of quantity: The example of damage awards on mock civil juries. Journal of Personality and Social Psychology, 73, 703-718.

Davis-Stober, C. P., Budescu, D. V., Dana, J., \& Broomell, S. B. (2014, February 3). When is a crowd wise? Decision, 1, 79-101.

Dawes, R. M., van de Kragt, A. J., \& Orbell, J. M. (1988). Not me or thee but we: The importance of group identity in eliciting cooperation in dilemma situations: Experimental manipulations. Acta Psychologica, 68, 83-97.

De Dreu, C. K. W. (2007). Cooperative outcome interdependence, task reflexivity, and team effectiveness: A motivated information processing perspective. Journal of Applied Psychology, 92, 628-638.

De Dreu, C. K. W. (2010). Social conflict: The emergence and consequences of struggle and negotiation. In S. T. Fiske, D. T Gilbert, \& H. Lindzey (Eds.) Handbook of social psychology 5th edition, Vol. 2, (pp. 983-1023). New York, NY: John Wiley \& Sons.

De Dreu, C. K. W., Nijstad, B. A., \& Van Knippenberg, D. (2008). Motivated information processing in group judgment and decision making. Personality and Social Psychology Review, 12, 22-49.

Fjermestad, J., \& Hiltz, S. R. (1999). An assessment of group support systems experimental research: Methodology and results. Journal of Management Information Systems, 15, $7-$ 149. 
Gibbons, A. M., Sniezek, J. A., \& Dalal, R. S. (2003). Antecedents and consequences of unsolicited versus explicitly solicited advice. In D. Budescu (Chair), Symposium in Honor of Janet Sniezek. Symposium presented at the annual meeting of the Society for Judgment and Decision Making, Vancouver, BC.

Gigone, D., \& Hastie, R. (1993). The common knowledge effect: Information sharing and group judgment. Journal of Personality and Social Psychology, 65, 959-974.

Goldsmith, D. J., \& Fitch, K. (1997). The normative context of advice as social support. Human Communication Research, 23, 454-476.

Grofman, B., \& Owen, G. (Eds.). (1986). Decision research (Vol. 2). Greenwich, CT: JAI Press.

Halevy, N., Bornstein. G., \& Sagiv, L. (2008). "In-group love" and "out-group hate" as motives for individual participation in intergroup conflict: A new game paradigm. Psychological Science, $19,405-11$.

Harvey, N. \& Fisher, I. (1997). Taking advice, accepting help, improving judgment and sharing responsibility. Organizational Behavior and Human Decision Processes, 70, 117-133.

Haseman, P. S., \& Ramamurthy, K. (2004). Collective memory support and cognitive conflict group decision-making: An experimental investigation. Decision Support Systems, 36, $261-281$.

Hastie, R., \& Kameda, T. (2005). The robust beauty of majority rules in group decisions. Psychological Review, 112, 494-508.

Hinsz, V. B. (1990). Cognitive and consensus processes in group recognition memory performance. Journal of Personality and Social Psychology, 59, 705-718. 
Hinsz, V. B. (1999). Group decision making with responses of a quantitative nature: The theory of social decision schemes for quantities. Organizational Behavior and Human Decision Processes, 80, 28-49.

Hinsz, V. B., Tindale, R. S., \& Vollrath, D. A. (1997). The emerging conception of groups as information processors. Psychological Bulletin, 121, 43-64.

Hogg, M. A. (2018). Social identity theory. In P. J. Burke (Ed.), Contemporary social psychological theories (2nd ed.) (pp. 112-138). Stanford, CA: Stanford University Press.

Homan, A. C., van Knippenberg, D., van Kleef, G. A., \& De Dreu, C. K. W. (2007). Bridging faultlines by valuing diversity: Diversity beliefs, information elaboration, and performance in diverse work groups. Journal of Applied Psychology, 92, 1189-1199

Hora, S. C., Fransen, B. R., Hawkins, N., \& Susel, I. (2012). Median aggregation of probabilistic judgments. Paper presented at INFORMS meeting, Phoenix, AZ.

Janis, I. (1982). Groupthink (2nd Ed.). Boston, MA: Houghton-Mifflin.

Johnson, T. R., Budescu, D. V., Wallsten, T. S. (2001). Averaging probability judgments: Monte Carlo analyses of asymptotic diagnostic value. Journal of Behavioral Decision Making, $14,123-140$.

Kahn, J. P., \& Rapoport, A. (1984). Theories of coalition formation. Hillsdale, NJ: Lawrence Erlbaum Associates.

Kameda, T., \& Tindale, R. S. (2004). Evolutionary/adaptive thinking as a meta-theory for systematic group research: An extended "fungus-eater" approach. Group Processes and Intergroup Relations, 7, 299-304.

Kameda, T., \& Tindale, R. S. (2006). Groups as adaptive devices: Human docility and group aggregation mechanisms in evolutionary context. In M. Schaller, J. A. Simpson, \& D. T. 
Kenrick (Eds.), Evolution and social psychology (pp. 317-342). New York, NY:

Psychology Press.

Kameda, T., Tindale, R. S., \& Davis, J. H. (2003). Cognitions, preferences, and social sharedness: Past, present and future directions in group decision making. In S. L. Schneider \& J. Shanteau (Eds.), Emerging perspectives on judgment and decision research (pp. 458-485). Cambridge, UK: Cambridge University Press.

Kerr, N. L., MacCoun, R. J., \& Kramer, G. P. (1996). Bias in judgment: Comparing individuals and groups. Psychological Review, 103, 687-719.

Kerr, N. L., \& Tindale, R. S. (2004). Group performance and decision making. Annual Review of Psychology, 55, 623-656.

Kerr, N. L., \& Tindale, R. S. (2011). Group-based forecasting: A social psychological analysis. International Journal of Forecasting, 27, 14-40.

Krueger, J. L. (2003). Return of the ego-self-referent information as a filter for social prediction: comment on Karniol (2003). Psychological Review, 110, 585-590.

Kruglanski A. W., \& Webster, D. M. (1996) Motivated closing of the mind: "seizing” and “freezing." Psychological Review, 103, 263-283.

Larrick, R. P., Mannes, A. E., \& Soll, J. B. (2012). The social psychology of the wisdom of crowds. In J. I. Krueger (Ed.), Social judgment and decision making (pp. 227-242). New York, NY: Psychology Press.

Larrick, R. P., \& Soll, J. B. (2006). Intuitions about combining opinions: Misappreciation of the averaging principle. Management Science, 52, 111-127. 
Larson, J. R. Jr., Foster-Fishman, P. G., \& Franz, T. M. (1998). Leadership style and the discussion of shared and unshared information in decision making groups. Personality and Social Psychology Bulletin, 24, 482-495.

Laughlin, P. R. (1980). Social combination processes of cooperative, problem-solving groups on verbal intellective tasks. In M. Fishbein (Ed.), Progress in social psychology (Vol. 1, pp. 127-155). Hillsdale, NJ: Lawrence Erlbaum Associates.

Laughlin, P. R. (2011). Group problem solving. Princeton, NJ: Princeton University Press.

Laughlin, P. R., \& Ellis, A. L. (1986). Demonstrability and social combination processes on mathematical intellective tasks. Journal of Experimental Social Psychology, 22, 177-189.

Lee, M. D., S. Zhang, J. Shi. (2011). The wisdom of the crowd playing the Price is Right. Memory \& Cognition, 39, 914-923.

Levine, J. M., \& Kerr, N. L. (2007). Inclusion and exclusion: Implications for group processes. In A. E. Kruglanski \& E. T. Higgins (Eds.), Social psychology: Handbook of basic principles (2nd ed., pp. 759-784). New York, NY: Guilford.

Littlepage, G. E., Robison, W., \& Reddington, K. (1997). Effects of task experience and group experience on performance, member ability, and recognition of expertise. Organizational Behavior and Human Decision Processes, 69, 133-147.

Lorenz, J., Rauhut, H., Schweitzer, F., \& Helbing, D. (2011). How social influence can undermine the wisdom of crowd effect. Proceedings of the National Academy of Sciences, USA, 108, 9020-9025.

Lu, L., Yuan, Y., \& McLeod, P. L. (2012). Twenty-five years of hidden profile studies: A metaanalysis. Personality and Social Psychology Review, 16, 54-75. 
MacCoun, R., \& Kerr, N. L. (1988). Asymmetric influence in mock jury deliberations: Jurors' bias for leniency. Journal of Personality and Social Psychology, 54, 21-33.

McCallum, D. M., Harring, K., Gilmore, R., Drenan, S., Chase, J., Insko, C. A., \& Thibaut, J. (1985). Competition between groups and between individuals. Journal of Experimental Social Psychology, 21, 310-320.

Mellers, B., Ungar, L., Baron, J., Ramos, J., Burcay, B., Fincher, K. . . Tetlock, P. E. (2014). Psychological strategies for winning a geopolitical forecasting tournament. Psychological Science, 25, 1106-1115.

Messick, D. M. (2006). Ethics in groups: The road to hell. In E. Mannix, M. Neale, \& A. Tenbrunsel (Eds.), Research on Managing Groups and Teams: Ethics in Groups, 8. Oxford, UK: Elsevier Science Press.

Michaelson, L. K., Watson, W. E., \& Black, R. H. (1989). A realistic test of individual vs. group decision making. Journal of Applied Psychology, 74, 834-839.

Mojzisch, A., \& Schulz-Hardt, S. (2010). Knowing others' preferences degrades the quality of group decisions. Journal of Personality and Social Psychology, 98, 794-808.

Morgan, P. M., \& Tindale, R. S. (2002). Group vs. individual performance in mixed motive situations: Exploring an inconsistency. Organizational Behavior and Human Decision Processes, 87, 44-65.

Nijstad, B. A. (2009). Group performance. New York, NY: Psychology Press.

Paulus, P. B., \& Nijstad, B. A. (Eds.). (2003). Group creativity: Innovation through collaboration. Oxford, UK: Oxford University Press.

Postmes, T., Spears, R., \& Cihangir, S. (2001). Quality of decision making and group norms. Journal of Personality and Social Psychology, 80, 918-930. 
Resnick, L. B., Levine, J. M., \& Teasley, S. D. (Eds.). (1991). Perspectives on socially shared cognition. Washington, DC: American Psychological Association.

Rohrbaugh, J. (1979). Improving the quality of group judgment: Social judgment analysis and the Delphi technique. Organizational Behavior and Human Performance, 24, 73-92.

Rowe, G., \& Wright, G. (1999). The Delphi technique as a forecasting tool: Issues and analysis. International Journal of Forecasting, 15, 353-375.

Rowe, G., \& Wright, G. (2001): Expert opinions in forecasting: Role of the Delphi technique. In J. S. Armstrong (Ed.), Principles of forecasting: A handbook of researchers and practitioners (pp. 125-144). Boston, MA: Kluwer Academic Publishers.

Schelling, Thomas C. (1960). The strategy of conflict. Cambridge, MA: Harvard University Press.

Schrah,G. E., Dalal,R. S.,\&Sniezek, J. A.(2006). No decision-maker is an island: Integrating expert advice with information acquisition. Journal of Behavioral Decision Making, 19, $43-60$.

Simmons, J. P., Nelson, L D., Galak, J., and Frederick, S. (2011). Intuitive biases in choice vs. estimation: Implications for the wisdom of crowds. Journal of Consumer Research, 38, $1-15$.

Sheffey, S., Tindale, R. S., \& Scott, L. A. (1989). Information sharing and group decisionmaking. Paper presented at the Midwestern Psychological Association Annual Convention, Chicago, IL.

Smith, C. M., Dykema-Engblade, A., Walker, A., Niven, T. S., \& McGrough, T. (2000). Asymmetrical social influence in freely interacting groups discussing the death penalty: 
A shared representations interpretation. Group Processes and Intergroup Relations, 3 , $387-401$.

Sniezek, J. A., \& Buckley, T. (1995). Cueing and cognitive conflict in judge-advisor decision making. Organizational Behavior and Human Decision Processes, 62, 159-174.

Sniezek, J. A., \& Van Swol, L. M. (2001). Trust, confidence, and expertise in a judge-advisor system. Organizational Behavior and Human Decision Processes, 84, 288-307.

Soll, J. B., \& Larrick, R. P. (2009). Strategies for revising judgments: How (and how well) people use others' opinions. Journal of Experimental Psychology: Learning, Memory, and Cognition, 35, 780-805.

Soll, J. B., \& Mannes, A. E. (2011). Judgmental aggregation strategies depend on whether the self is involved. International Journal of Forecasting, 27, 81-102.

Sorkin, R. D., Hays, C., \& West, R. (2001). Signal detection analysis of group decision making. Psychological Review, 108, 183-201.

Sorkin, R. D., West, R., \& Robinson, D. E. (1998). Group performance depends on the majority rule. Psychological Science, 9, 456-463.

Stasser, G. (1999). A primer of Social Decision Scheme Theory: Models of group influence, competitive model-testing, and prospective modeling. Organizational Behavior and Human Decision Processes, 80, 3-20.

Stasser, G., \& Dietz-Uhler, B. (2001). Collective choice, judgment, and problem solving. In M. A. Hogg \& R. S. Tindale (Eds.), Blackwell handbook of social psychology: Group processes (pp. 31-55). Oxford, UK: Blackwell Publishing 
Stasser, G., \& Titus, W. (1985). Pooling of unshared information in group decision making: Biased information sampling during discussion. Journal of Personality and Social Psychology, 48, 1467-1478.

Stasser, G., Vaughan, S. I., \& Stewart, D. D. (2000). Pooling unshared information: The benefits of knowing how access to information is distributed among members. Organizational Behavior and Human Decision Processes, 82, 102-116.

Stawiski, S., Tindale, R. S., \& Dykema-Engblade, A. (2009). The effects of ethical climate on group and individual level deception in negotiation. International Journal of Conflict Management, 20, 287-308.

Steiner, I. (1972). Group process and productivity. New York, NY: Academic Press.

Stewart, D. D., \& Stasser, G. (1995). Expert role assignment and information sampling during collective recall and decision making. Journal of Personality and Social Psychology, 69, $619-628$.

Stewart, D. D., \& Stasser, G. (1998). The sampling of critical, unshared information in decisionmaking groups: The role of an informed minority. European Journal of Social Psychology, 28, 95-113.

Surowiecki, J. (2004). The wisdom of crowds. New York, NY: Doubleday.

Sunstein, C. R., Hastie, R., Payne, J. W., Schkade, D. A., \& Viscusi, W. K. (2002). Punitive damages: How juries decide. Chicago, IL: University of Chicago Press.

Tindale, R. S. (1989). Group vs. individual information processing: The effects of outcome feedback on decision-making. Organizational Behavior and Human Decision Processes, $44,454-473$. 
Tindale, R. S. (1993). Decision errors made by individuals and groups. In N. Castellan, Jr., (Ed.), Individual and group decision making: Current issues (pp. 109-124). Hillsdale, NJ: Lawrence Erlbaum Associates.

Tindale, R. S., \& Kameda, T. (2000). Social sharedness as a unifying theme for information processing in groups. Group Processes and Intergroup Relations, 3, 123-140.

Tindale, R. S., Nadler, J., Krebel, A., \& Davis, J. H. (2001). Procedural mechanisms and jury behavior. In M. A. Hogg \& R. S. Tindale (Eds.), Blackwell handbook in social psychology: Group processes (pp. 574-602). Oxford, UK: Blackwell Publishers.

Tindale, R. S., Smith, C. M., Dykema-Engblade, A., \& Kluwe, K. (2012). Good and bad group performance: Same process_-different outcome. Group Processes and Intergroup Relations, 15, 603-618.

Tindale, R. S., Smith, C. M., Thomas, L. S., Filkins, J., \& Sheffey, S. (1996). Shared representations and asymmetric social influence processes in small groups. In E. Witte \& J. Davis (Eds.), Understanding group behavior: Consensual action by small groups (Vol. 1, pp. 81-103). Mahwah, NJ: Lawrence Erlbaum Associates.

Triplett, N. (1898). The dynamogenic factors in pacemaking and competition. Journal of Psychology, 9, 507-533.

Tversky, A., \& Kahneman, D. (1974). Judgment under uncertainty: Heuristics and biases. Science, 185, 1124-1131.

Van de Ven, A. H., \& Delbecq, A. L. (1971). Nominal vs. interacting group processes for committee decision-making effectiveness. Academy of Management Journal, 14, 203212. 
Vinokur, A., \& Burnstein, E. (1974). The effects of partially shared persuasive arguments on group induced shifts: A group problem solving approach. Journal of Personality and Social Psychology, 29, 305-315.

Vroom, V. H., and Yetton, P. Leadership and Decision-Making. Pittsburgh, PA: University of Pittsburgh Press, 1973.

Weber, B., \& Hertel, G. (2007). Motivation gains of inferior group members: A meta-analytical review. Journal of Personality and Social Psychology, 93(6), 973-993.

Wegner, D. M. (1987). Transactive memory: A contemporary analysis of the group mind. In B. Mullen \& G. R. Goethals (Eds.), Theories of group behavior (pp. 185-208). New York, NY: Springer-Verlag.

Wildschut, T., Pinter, B., Vevea, J. L., Insko, C. A., \& Schopler, C. A. (2003). Beyond the group mind: A quantitative review of the interindividual-intergroup discontinuity effect. Psychological Bulletin, 129, 698-722.

Wolfers, J., \& Zitzewitz, E. (2004). Prediction markets. Journal of Economic Perspectives, $18(2), 107-126$.

Yaniv, I. (2004). Receiving other people's advice: Influence and benefits. Organizational Behavior and Human Decision Processes, 93, 1-13

Yaniv, I. \& Choshen-Hillel, S. (2012). When guessing what another person would say is better than giving your own opinion: Using perspective-taking to improve advice-taking. Journal of Experimental Social Psychology, 48, 1022-1028.

Yaniv, I., \& Kleinberger, E. (2000). Advice taking in decision making: egocentric discounting and reputation formation. Organizational Behavior and Human Decision Processes, 83, 260-281. 